\title{
Muscularis Mucosa
}

National Cancer Institute

\section{Source}

National Cancer Institute. Muscularis Mucosa. NCI Thesaurus. Code C33149.

A thin layer of smooth muscle fibers found as a part of the tunica mucosa in the gastrointestinal tract and urinary bladder deep to the lamina propria mucosae. 